\title{
Covid-19's impact in the Angolan Higher Education Subsystem
}

\author{
Adília Mendonça da Costa e Silva Gaspar ${ }^{a, *}$
}

a Department of Accounting and Management, Faculty of Economics, Universidade Mandume ya Ndemufayo, Lubango, Angola.

*Corresponding author Email: asilva@fe.umn.ed.ao

DOI: https://doi.org/10.54392/ajir2212

Received: 29-11-2021; Revised: 08-02-2022; Accepted: 10-02-2022; Published: 12-02-2022

Abstract: Pandemic caused by Covid-19 revealed the weaknesses of many governments management. The classes shutdown showed the Angolan government the importance of distance learning for a society development. This work aimed to check challenges the Angolan State faced, in order to carry on the curriculum plans during this pandemic period, as well as some obstacles faced by students and teachers, as main protagonists in the teaching-learning process, as the lessons they took from it. Thus, a conversation with some students from the province of Huila in Angola, was organized. It was oriented by a teacher locally and monitored by the author. The author spoke with some teachers too. We could conclude that the pandemic really showed the lack of investment the Angolan State in education. In case they want to have a quality education, it is essential more investment in education, and especially in teachers education and their motivation. Not forgetting the need to invest more in technology, which is relevant nowadays for the non-stoppage of education and, consequently, the country's development.

Keywords: Covid-19, Pandemic, Education, Higher education in Angola, Pandemic in Angola

\section{Introduction}

The world became aware of the new SARS-Cov2 coronavirus existence at the end of 2019, and in such short time (beginning 2020) spread all over the world, turning into a rather frightening pandemic, causing states of emergency decreed around the world.

Several measures were taken by the countries, such as travel restrictions, social distancing, isolation measures, quarantines, campus and borders closing, and mainly on-site classes suspension with the purpose to avoid Covid-19 contamination spread. It is clear that this suspension is having a dramatic impact, obviously, affecting the education sector and also several countries economic dynamics. A drastic reduction in the internationalization of education can be seen (Recio \& Colella, 2020), being exchange students the most affected, representing, in turn, considerable losses for several higher education institutions. As a result, it is shown distance learning strategies extension for some countries and the establishment of the same for others (UNESCO, 2020). On the other side, a vast demand for researches related to Covid-19 was observed, exactly solutions search for the crisis in the figure of vaccines and other innovation actions, while non related researches for solutions search (but in the academic sphere) to the crisis caused by Covid, have faced countless difficulties related to access to laboratories, libraries, archives, and others. (Recio \& Colella, 2020). On the other hand, closing schools affected the psychological students behavior, as well as their families and teachers (Ribeiro et al., 2021). Teachers had to learn another teaching methods to adapt to the new teaching methods (Ramos-Pla, Bravo \& Alarcia, 2021), and be able to teach them to the students that had similar problems.

Despite students internationalization and mobility limitations and research activities disruption due to restrictions of researchers mobility (Gaebel, 2020), some institutions point out to positive experiences related to elearning systems operations and students participation rates in online classes (Hungarian Rector's Conference, 2020).

It is our intention to show, with this work, the main difficulties the Angolan State faced, with the pandemic emergence, and the importance of a bigger investment in education, on the one side, and on the other side, to 
realize how this new achievement affected the country student population's life (students and teachers), which changes came to their lives, which difficulties and obstacles they have faced and lessons learned.

\section{Literature review}

UNESCO (2020) reveals that several governments effort to implement distance learning, in scale, at all education levels, provides valuable lessons that can establish foundations for long-term goals regarding the construction of wider, inclusive and flexible educational systems, after COVID-19 pandemic has been overcome. Governments had to learn that traditional educational institutions and policies no longer answer to this new reality (Blankenberger \& Williams, 2020). Many countries intensified distance learning as a strategic escape to reduce possible pedagogical damage, assuring national education programs continuity and their safety regarding this new reality. An enquiry made by the European Universities Association in 2020, states that $96 \%$ of institutions adopt distance learning and only $4 \%$ provide face-to-face teaching in some faculties (European Universities AssociationEUA, 2020). Angola is one of the countries that was forced to establish distance learning strategies in order to avoid a catastrophe in terms of education. On March $3^{\text {rd }}, 2020$, the Angolan State approved the distance learning modalities and semi-attendance teaching for the higher education subsystem (Presidential Decree $n^{0}$ 59/20, of March ${ }^{1}$ ), after rejecting, for so long, recognizing any students documentation who had performed distance and/or semi-attendance learning abroad. Distance learning, according to UNESCO (2020), is synonym of online education, e-learning, distance education, correspondence education, external studies, flexible learning and massive open online courses. Being distance learning strategy a result of the current pandemic, it is a set of sectoral measures taken by different governments in order to continue students curricular studies, as well as other regular educational activities when schools and other educational institutions are closed, requiring that learning activities to be reviewed, and alternative learning program solutions are planned and provided with the support of teachers, the educational community in collaboration with students and their families, for these strategies to be successful. Some institutions, instead of fully embracing online education, preferred to operate in "Remote Emergency Learning" mode (Recio \& Colella, 2020). Emergency Remote Teaching is considered teaching offers improvised mode, curricular units, by HEIs, making adaptations using online resources, not considering students and teachers reality important aspects, and also the pedagogical and technological aspects involved in the process (Gusso, et al., 2020). These authors point to the students low academic performance, school failure increase, higher education evasion probability increase, and teachers fatigue, who are usually overwhelmed by multiple activities and the challenges of dealing with technology in order to promote teaching, as the possible consequences of emergency remote learning. There is, emergency remote teaching adapts to existing situations such as Covid-19, which required the closure of HEIs, not being regulated, without properly established rules, as distance learning.

Distance learning requires technologies use, digital systems and programs as essential tools for its accomplishment. Therefore, in some countries, HEIs, in coordination with their governments, international organizations, private sector partners and civil society, have tried to provide education through a set of technologies to ensure teaching and learning (UNESCO, 2020). And this situation has been changing the countries education system, demanding an adaptation of all those involved in the teaching-learning process, from teachers, students and their families, governments and society in general. Teachers and students are the most affected, since they are the ones who are directly dealing with the learning process or not, several programs handling, applications and tools that are now being used more frequently in the teaching process. This entire process of transforming on site classes to the virtual mode, without changing the previously designed curriculum or the teaching methodology as a consequence of the emergence of Covid-19, is defined as Corona teaching. And therefore, teachers, with some acquired experience, for example, through distance postgraduate programs and appropriate digital resources, probably do not have great difficulties in assuring the continuity and do not suffer from the Corona teaching Syndrome (IESALC \& UNESCO, 2020). Corona teaching Syndrome is related to the effects that this abrupt migration from face-to-face teaching to online teaching has caused to the teachers.

1 Presidential Decree no 321/20, December 24th (Republic Diary no 209, Ia Serie) approves Distance and Semi On-Site Teaching Modalities Regulation in Primary and Secondary Education. 
Main difficulties

This pandemic showed the multiple mistakes the Angolan State made, regarding education system management, in particular, higher education subsystem. Rashid and Yadav (2020) say that, beside exposing current educational systems vulnerabilities and deficiencies for both developed and developing countries, this crisis also emphasized the need for developing digital literacy. Blankenberger and Williams (2020) claimed that higher education produces externalities such as the value for a population of having a workforce, consumers and educated citizens, which benefit those who are not directly linked to the teaching-learning process, therefore it is one of the main reasons why governments invest highly in higher education. However, the Angolan government investment in education and, especially, in higher education is shown as practically insignificant. Just to get an idea, on March 3rd, 2021, the Faculty of Economics Dean at the José Eduardo dos Santos University, in the province of Huambo, Angola, stated to the local press that, since 2014 that institution has not received budget allocations, resulting in costs reduction with the investment in quality training ${ }^{2}$. This institution problems, result of funding lack, unable teaching and learning quality development, since there is no investment in projects that can stimulate the process, such as scientific research investment. The Dean highlighted that the institution does not have its own facilities, lacks teachers, and the funding shortage does not allow it to proceed with the teachers training and laboratories settlement project. However, it is a current problem, not only in that institution, but in most, if not all country public institutions. How can we have quality education if there is no investment and, above all, there is no will to solve these kind of problems? The IESALC and UNESCO report (2020) states that the families with internet percentage in Africa is relatively low, around $17 \%$. The distance learning strategy adopted worldwide, as an answer to the current reality in Angola, shows ineffective due to the considered basic conditions lack for its functioning: main element lacks internet - both at HEIs level as well as the families, who mostly have an income far below 200 euros a month. Besides internet, electricity absence remains a serious problem. Even after 19 years of peace, the problem has not been solved: the vast majority of Angolan families live with electricity and running water restrictions. Gusso et al (2020), said that, besides students limited or non-existent access to the required technologies for learning, the systems adaptation and implementation process exposes other problems such as, in some cases, teachers psychological support absence, teaching low quality resulting in activities planning lack, teacher overload of work and students demotivation. Many of these issues have already become debate topics between the various HEIs in Angola: the need for constant pedagogical training, teachers shortage, forcing the few existing ones to become versatile in order to meet the needs of the HEIs in which they teach ${ }^{3}$, the teachers low qualification, among others. The main question is, what to say about this moment when much more is demanded of all those involved in the teaching-learning process? In a time, great effort and collaboration are required from the teachers so that the adopted strategies are successful, it is visible the Angolan teachers lack of motivation. The arguments are all focused on the salary part, since nowadays the basic food basket cost in Angola is above $75 \%$ a higher education teacher salary, Assistant Category ${ }^{4}$, whose salary difference is not much in comparison to teachers in the Teachers Category. All of this is the result of runaway inflation, once everything in the country revolves around the US dollar, and education serious investment is reflected, primarily, in the citizens quality of life. These insignificant salaries do not allow them to have a reasonably dignified life, such as owning their house or transport (not forgetting that Angola is a country that does not have public transports), let alone investing personally in activities scientific and postgraduate training possibility?

Distance learning requires student's more discipline and commitment (IESALC \& UNESCO, 2020), stronger involvement and communication with students (Recio \& Colella, 2020), which, in many cases, questions the student's learning quality level. It also requires a high level of self-directed learning by the student and study skills, which should be supported through new teaching, learning and guidance strategies (UNESCO, 2020), as well as detailed training, content adjustment to the used tool. and multifaceted investment (Recio \& Colella, 2020).

Being distance and semi-distance learning solutions to the Covid-19 pandemic, Angola's Higher Education, Science, Technology and Innovation Ministry (MESCTI) started to develop an electronic platform to balance these education systems at this stage. of Covid-19. It is a tool that will contain several features, allowing the material

\footnotetext{
2 Information may be found Angop newspaper, March $3^{\text {rd }}, 2021$

${ }^{3}$ It is usual to find in Angola a teacher that lectures in 3 or more teaching institution and disciplines even without knowledge.

${ }^{4}$ Information obtained in Angola's newspaper, April 30th, 2021.Interview was conceded by Teachers National Union Presidents, Guilherme Silva, and readjusted by HE teachers.
} 
availability, and to monitor student's learning when receiving classes, making it possible to balance semi-attendance and distance learning, and it will be distributed to educational institutions. The current Higher Education Secretary of State, Eugénio Silva, in an interview to Jornal de Angola on August $22^{\text {nd }}, 2020$, said that even with this platform creation, not all will have access, as not everyone has internet and digital media, being this the dilemma, they are trying to overcome: "trying to maximize education and preserve exclusion possibility that technologies cause in Angola". The Higher Education Secretary of State also stated that, according to a ministry report, until May 2020, $50 \%$ of HEIs reported that they were able to return to classes, using platforms, but only two thirds of students had access to distance learning. Therefore, when the problem is not the internet, or students unable to purchase a computer, it will be associated with electricity lack, since in many country regions, the energy supply system is restricted: day in, day out (as an example, the city of Lubango, Huíla province).

In some cases, where subjects require laboratory experiments, practical experiences or internships, distance learning becomes much more complicated (European University Association-EUA, 2020; Blankenberger \& Williams, 2020). This obliges HEIs to develop or modify their physical and social technologies in order to create alternative paths for practical classes, such as medical students internships and teachers course (Blankenberger \& Williams, 2020), or students who need to make some experiments in laboratories.

\section{Some consequences of Covid-19}

One of the main measures taken by the various countries to avoid the progressive infection by Covid-19, had its focus in some economic and social activities closure, with emphasis on education, since educational establishments are considered natural and high contact between those involved in the teaching-learning process. For example, most European universities closed their campuses in March 2020 (European University AssociationEUA, 2020), as well as HEIs in Latin America and the Caribbean (IESALC \& UNESCO, 2020), as well as African countries, with particular reference to Angola, where HEIs temporarily closed their activities as of March 24th (Executive Decree $n^{\circ} 148 / 20$, of April $14^{\text {th }}$ ), remaining suspended for an indefinite period (Executive Decree $n^{\circ}$ $201 / 20$ of July $9^{\text {th }}$ ).

With this situation, many students saw their dreams postponed and projects canceled, especially those who were in their formation final year. According to the IESALC and UNESCO report (2020), a study carried in March 2020 last week, among higher education students in the US shows that, about 75\% have anxiety and depression problems as a result of the crisis. This same report says that, despite being a few months without studying, moving later to the distance learning system, through videoconferences and online classes, students and their families continued to bear costs associated with their academic training, for example, fees payment. In Angola, it was decreed that private and public-private ${ }^{5}$ EI students should pay tuition fees during the State of Emergency and State of Public Calamity (Executive Decree No. 157/20, April 22 ${ }^{\text {nd }}$; Executive Decree No. $190 / 20$, of July $2^{\text {nd }}$; Executive Decree No. 242/20, of October $6^{\text {th }}$ ).

Students mobility, with this new social reality, is the most affected. The study carried out by the European University Association-EUA (2020) considers students internationalization and mobility to be the first victim regarding education, since two thirds of institutions saw their student mobility affected. The OECD (Organization for Economic Cooperation and Development) in 2017 estimated that more than 5.3 million students studied outside its territory (IESALC \& UNESCO, 2020). Due to the low quality of HEIs in some African countries, students and governments in general seek abroad, mainly Europe, America and some countries in Asia, to graduate. In 2018, Chinese government reported that 81,562 African students were studying in China, believing 5000 were in Wuhan city (IESALC \& UNESCO, 2020). However, according to that same report by IESALC and UNESCO, with this current pandemic situation, the Education American Council projected that international application in the US would fall by $25 \%$ in 2021 .

In Angola, Higher Education Science, Technology and Innovation current minister, PhD Maria do Rosário Sambo, revealed, in the Angolan parliament on May $18^{\text {th }}$ 2020, that the Angolan State spends around USD $2,200,712.69$ per month in the scholarships complement payment for students who are abroad. According to the same, the Angolan Scholarships Management National Institute (INAGBE) controls around 2566 scholarship holders abroad, $50 \%$ of whom are in Cuba. Most of these scholarship holders, $89 \%$ are in undergraduate courses, $5.6 \%$ in

${ }^{5}$ Public HEI do not charge fees.

Asian J. Interdicip. Res, 5(1) (2022), 10-18|13 
masters and $4.1 \%$ in doctorate. Due to this pandemic situation, many students returned to the country. Around 400 students returned to the country from the Russian Federation. On April 27 ${ }^{\text {th }} 2021$, INAGBE's Director, Milton Chivela, in an interview to Journal Nova Gazeta, stated that INAGBE controls approximately 1900 scholarship students abroad, and that the government's project to award 300 scholarships annually to the best universities in the world, despite the current situation, is still in progress, and with this project the state spends more than 50 million US dollars annually. That is to say, there was a slight reduction in scholarship holders number who are abroad.

The European University Association-EUA report (2020) says that there was also a disruption in research activities, since there were restrictions on the researchers international mobility, resulting in obstacles to collaboration for research and closing of laboratories.

\section{Methodology}

It is a qualitative research, since the analysis is descriptive, offering the problem under study's a better view and understanding (Reis, 2018). The study was carried in Lubango city, province of Huila in Angola. Considering the difficulties with traveling to collect information, due to the pandemic, it was carried out with 3 colleagues help. They were given basic questions such as "what changes has the pandemic brought to your life? What were the biggest obstacles found? What lessons did you learn? After their purpose's brief explanation, students groups were organized and led a small discussion. However, the sample considered a group of students from 3 HEIs in the Lubango city ${ }^{6}$. The number was quite low, since the current situation, some institutions have redefined their teaching methods and reorganized their classes: some classes have been bisected to fulfil social distancing measures due to the impossibility of having online classes ${ }^{7}$.

Six groups were composed, in which 5 groups were composed of 7 students each and a group composed of only 6 students, totaling 41 students, and following each institution prevention rules. Discussions took place in a two weeks period ${ }^{8}$.

Although security measures were imposed due to Covid-19, such as distancing and masks use, we can say that the discussion carried out had a "focus group" same characteristics, which is a structured interview with a small group of people in a debate on a certain subject, allowing relevant information gathering about the subject under debate.

We also placed the same questions to 8 teachers, some of whom teach at more than one educational institution. And this online interview work was developed between May 11th to May $28^{\text {th }}, 2021$.

\section{Results and discussion}

After raising the questions, starting with the changes that the pandemic brought to the students lives. They were unanimous in stating that the main change is associated with mobility restrictions, as well as coexistence new rules that were imposed in order to contain the virus spread, such as the mandatory masks use and distance.

Distance learning initial attempt, through internet use was unsuccessful, since there are no conditions at the institutional level, nor the students, which forced the institutions to return to classes applying State imposed measures, to the general society. However, the time during which classes were interrupted, around 7 to 8 months, students point out as the main reason for the return to classes adapting difficulty:

"The first main change was contents difficult adaptation after confinement time" (Group 3).

"... we've been away from curriculum materials for a long time! And when we returned to school we faced a totally different reality, we had to reinvent ourselves due to the pandemic-imposed restrictions." (Group 1).

\footnotetext{
${ }^{6}$ We spoke to 3 colleagues that lecture in different institutions.

${ }^{7}$ Reminder that not everyone has internet access and the few who have, there is great access difficulty.

${ }^{8}$ Economy Faculty, Mandume Ya Ndemufayo University in Lubango city, Huíla province in Angola, for example, divided the classes in two and each group has classes with the same teacher, once a week.
} 
Others even stated that "after confinement period, they had lost the study rhythm and there were times when they had no will to study again..." (Group 5).

On the other hand, "...the use of masks during classes, associated with the distance between students and between teachers and students, makes it difficult to understand the content and sometimes forces both teachers and students to scream to be understood by their colleagues" (Group 2).

"...the person makes a huge effort to understand the class in the gym, communication with teachers, access to study materials..." (Group 3).

One of the group (Group 6) highlighted that the biggest difficulty faced is the fact that "...teaching and learning process requires direct interaction between teachers and students, requiring even more interaction between the students themselves, and because of Covid -19 were forced to reduce this contact, which could result in a school performance reduction... the interaction with teachers and other students was fundamental, and this was taken away from us in the first weeks".

The students also stated that the interaction between students, as well as between students and professors, became very virtual, which they considered something interesting, since technology is indispensable nowadays. However, most students do not have the economic capacity to obtain equipment such as computers or smartphones and internet installation or even mobile data purchase.

Students argued that the pandemic brought many changes and challenges, as it is a new experience, and in the beginning, it was very difficult due to the new reality adaptation. They also addressed the fact that teachers are running with the programmed contents due to the reduced time of classes:

"... the teachers are running with the lessons, and this ends up reducing in percentage what should be learned about each topic. But, on the other hand, it is serving to develop the spirit of research and the search for information related to subjects in other extra-curricular fields." It can be considered a positive aspect of the pandemic.

Another positive aspect is the fact that allows to detect health system weaknesses: "Covid-19 taught us to be cautious and prudent when it comes to hygiene and protection, it detected many health systems weaknesses nowadays, and thanks to it, they are trying to reverse the situation, investing in in our country health sector" (Group 2).

This pandemic also showed the need for more investment in HEIs. "We need proper computer rooms ... even if students do not have a computer with internet at home, they could come to the institution and do some research..."

Some students from the Economics Faculty at the Mandume Ya Ndemufayo University, which adopted bimonthly class system, stated that they enjoyed the adopted methodology, as it allowed them to better study the given content and had good results, being more effective for them. On the other hand, other students argued that:

"Teaching and learning process does not stop, and it can not stop, since in a nation where there is no knowledge acquisition, there is no development. Teaching and learning process is very interactive and in that sense, the contact decrease between teaching and learning agents produces good results decrease"(Group 6).

There are also students who stated that this situation made them "rethink and redo the personal plans that were previously elaborated free of extraordinary situations" as Covid-19 case, but gave them more encouragement to rethink projects and keep them alive and flexible "maybe even better than the previous ones".

Finally, the students said they took their lesson:

- "Never leave anything for tomorrow because the future belongs to God".

- "Life is a breath and we should always make a difference. Love more your neighbor and forgive, there is no point in disagreement"

- "...life is the most valuable human asset...".

- "Every crisis brings an opportunity to improve". 
Regarding the teachers, the few who we spoked to, as expected, they pointed out that the new reality changed completely their routines and plans, both professionally and personally. First, school calendar had a sudden change. Before the pandemic, classes normally started in March and ended in December of each year. Due to the imposed complications by the Covid-19 pandemic that led educational institutions to suspend their activities for approximately 8 months (in Angola), government was forced to decree a new school calendar, from September to July, a calendar that was in force before Angola's independence.

Some teachers referred the difficulty they had restructuring their classes plans:

"Some classes are very large, such as first and second year classes that can have more than 40 students. And these classes had to be divided at least in two to comply social distancing measure ... all this was complicated because classes had to be doubled, one week to one group of students and another week to another group of students. The evaluation is worse in which we have to prepare several tests..."

Teachers say they feel more stressed because they see that work has been doubled and the income does not compensate, nor do they see benefits from the institution. On the other hand, they assign several responsibilities to the government for the lack of support to educational institutions. One of the professors stated that:

"At a time like this, when only artificial intelligence is talked about, we have institutions that are unable to have an Internet in good conditions. We can not search in the internet for at least 30 minutes because it does not work. That is why the online classes attempt failed. If we, as an institution do not have internet, how can we expect students to have internet at home?"

Initially, distance learning was planned, using internet as a resource. The country conditions do not allow it, starting with the institutions constant lack of electricity and then the internet is not the best.

"... for example, we tried to hold some meetings through google meet, but the internet was not the best, the signal constantly dropped or crashed and, therefore, the result was not the best... we have also tried via whatsapp and it was even worse..."

According to some teachers, pandemic showed the weaknesses not only of the Angolan education system, but mostly all the health system and the hygiene lack in the educational institutions. Most institutions do not have adequate toilets for teachers, administrative staff or students, since the structure itself is unsafe (without doors or windows), the lack of water in the bathrooms, often making them unusable.

Some teachers who are currently doing postgraduate studies abroad referred difficulties in completing their research, due to mobility restrictions and also the high rise of costs in the country, especially international air ticket.

"...the consequences for the country's economy are visible... We earn a salary that is currently equivalent to almost 500 US dollars at the bank exchange rate, which has a floating rate policy that only goes up and never goes down, and a ticket to Portugal, for example, right now it's almost triple our salary."

At a time like this, teachers claim for more investment in $\mathrm{HE}$, more investments both in terms of structures and in teacher training.

"... we who have family here, with this salary it is impossible for us to travel, to transfer money to Portugal for the expenses we incur there due to training. There are colleagues who ended up giving up on training because of the difficulties they encountered... the government is not granting scholarships. It is an exercise that we have to do with our salary and most times we have to choose between feeding the family here or investing in academic training. And on the other hand, when we are here in Angola, we are unable to carry out research: institutions have no databases to research articles, no libraries in conditions, associated with this is the lack of internet that we have already mentioned and also the fact of electricity constantly missing... it is practically impossible to talk about training in these conditions."

\section{Conclusion}

SARS Covid-19 virus emergence is playing the role of investment supervisor that has been made in terms of health and also education, particularly in higher education, which is our study object. For a long time, Angolan 
government's focus regarding education is to improve education quality. However, investments in education and higher education have been quite low compared to other ministries.

The government has been constantly talking about increasing the number of internal and external scholarships for teachers. But, however, it has only carried out internal and external scholarships, alleging a lack of foreign exchange, which leads teachers, who want to do postgraduate studies abroad to finance their own training. Teachers continue to claim for support in training, and more investments at the HEIs level. Universities will need to pay close attention in order to have teachers who are trained and equipped with digital technology so that there is a peaceful teaching-learning process. This reinforces the idea that the Angolan government needs to invest a lot, not only in infrastructures that are essential, but mostly in teachers who will train the local population, preparing them to be able to respond to situations similar to the current one, which requires greater knowledge at a technological level. Indeed, the Angolan Secretary of State for Science, Technology and Innovation Higher Education, Eugénio Silva, defends a new teaching and learning model creation in universities, adapted to the current epidemiological scenario, marked by Covid-19, and also the need for adequate infrastructure to the new context, as well as the use of technologies capable of ensuring the aforementioned model, which involves aggregating on-site, semi-distance and distance education modalities.

Online education, in addition to not ensuring equity, as not all students have their own computers or internet connection, students and teachers working time has become more diffuse and harder to reconcile family duties with professional ones, and also challenged students' assessment and the way to take exams. In Angola, the attempt to establish online education, failed right at the very beginning, as the internet connection was not only difficult for students, but also for the institutions themselves, not to mention that many students do not have a computer. Associated with this is the fact of the constant electricity restriction.

Regarding teaching improvement quality, only recently institutions have started to give greater importance to research and research production, as it became one of the main requirements for teachers' promotion. This, combined with the training high level, have been the main reasons for teachers, even without financial support, to seek postgraduate training abroad. In terms of education investment, if Angola continues this way, hybrid education accomplishment (online for some students and on-site for others) will remain just a dream. Recalling that for serious investments in education it implies that there are first improvements in basic social conditions, salaries, as well as teachers' motivation.

Regarding Coronateaching Syndrome, if online teaching was successful, Angolan teachers would probably suffer from Coronateaching Syndrome, since up to now distance learning was not recognized in the country, causing many Angolan teachers not to adhere to this type of modality and therefore have no experience on the subject.

Finally, the pandemic only came to show the Angolan government's management weaknesses, as well as the mistakes they have made over the years, recalling that the policies that have been defined based on totally different realities (the Angolan government has constantly adopted foreign countries models), without being subjected to a compatibility investigation, that is, for example, bringing to the country management models copied from other countries, it is not functional without a deep study about the reality which will be implemented.

\section{References}

Blankenberger, B., \& Williams, A.M., (2020) Covid and the impact on higher education: the essential role of integrity and accountability, Administrative Theory \& Praxis, 42(3) 404-423. https://doi.org/10.1080/10841806.2020.1771907

European University Association-EUA, (2020), European higher education in the Covid-19 crisis, International Association of Universities, Brussels.

Gaebel, M., (2020) European Higher Education in the Covid-19 crisis, Em I. A. Universities, Regional/National perspectives on the impact of Covid-19 on Higher Education (pp. 9-17), International Association of Universities, Paris. 
Gusso, H.L., Archer, A.B., Luiz, F.B., Sahão, F.T., de Luca, G.G., Henklain, M.H.O, Panosso, M.G, Kienen, N., Beltramello, O., Gonçalves, V.M., (2020) Ensino superior em tempos de pandemia: diretrizes à gestão universitária. Educação e Sociedade, 41, 1-26.

Hungarian Rectors' Conference, (2020) Hungarian response to Covid-19, Em I. A. Universities, Regional/National perspectives on the impact of Covid-19 on Higher Education (pp. 25-30) International Association of Universities, Paris.

IESALC, I.I., \& UNESCO, O.d., (2020) COVID-19 and higher education: today and tomorrow - Impact analysis, policy responses and recommendations, UNESCO, IESALC.

Ramos-Pla, A.; Bravo, I. A.; Alarcia, O.F. (2021). Analysis of Training Programs and Perception of Impact on Teaching Practices, Education Sciences, 11 (684) 1-12.

Rashid, S., \& Yadav, S.S., (2020) Impact of Covid-19 Pandemic on Higher Education and Research. Indian Journal of Human Development, 14(2), 340-343. https://doi.org/10.1177/0973703020946700

Recio, S.G., \& Colella, C., (2020) The world of higher education after Covid-19 - How Covid-19 has affected young universities, Yerun (Young European Research Universities), Brussels.

Reis, F.L., (2018) Investigação Científica e Trabalhos Académicos - Guia Prático, Edições Sílabo, Lda, Lisboa.

Ribeiro, L.M., Cunha, R.S., Silva, M.C.A.e., Carvalho, M., Vital, M.L., (2021). Parental Involvement during Pandemic times: Challenges and Opportunities, Education Sciences, 11 (302)2-17. https://doi.org/10.3390/educsci11060302

UNESCO, (2020) Distance learning strategies in response to COVID-19 school closures, UNESCO COVID-19 Education Response - Education Sector issue notes, 1-8.

Funding: No funding was received for conducting this study.

Conflict of Interest: The Author has no conflicts of interest to declare that they are relevant to the content of this article.

\section{About The License}

(C) The Author 2022. The text of this article is open access and licensed under a Creative Commons Attribution 4.0 International License

\section{Cite this Article}

Adília Mendonça da Costa e Silva Gaspar, Covid-19's impact in the Angolan higher education subsystem, Asian Journal of Interdisciplinary Research, 5(1) (2022) 10-18. https://doi.org/10.54392/ajir2212 